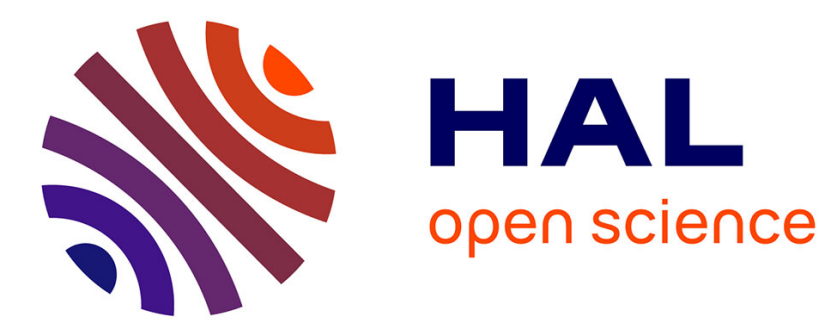

\title{
Biomedical Monitoring Technologies and Future Healthcare Systems
}

Marie Chan, Eric Campo, Damien Brulin, Daniel Estève

\section{To cite this version:}

Marie Chan, Eric Campo, Damien Brulin, Daniel Estève. Biomedical Monitoring Technologies and Future Healthcare Systems. Journal of Science and Technology: Issue on Information and Communications Technology, 2017, 3 (1), pp.59-75. hal-01653965

\section{HAL Id: hal-01653965 https://hal.laas.fr/hal-01653965}

Submitted on 2 Dec 2017

HAL is a multi-disciplinary open access archive for the deposit and dissemination of scientific research documents, whether they are published or not. The documents may come from teaching and research institutions in France or abroad, or from public or private research centers.
L'archive ouverte pluridisciplinaire $\mathbf{H A L}$, est destinée au dépôt et à la diffusion de documents scientifiques de niveau recherche, publiés ou non, émanant des établissements d'enseignement et de recherche français ou étrangers, des laboratoires publics ou privés. 


\title{
Biomedical Monitoring Technologies and Future Healthcare Systems
}

\author{
Marie Chan, Eric Campo, Damien Brulin, and Daniel Estève
}

\begin{abstract}
Healthcare Systems (HCSs) throughout the world undergo important changes driven by aging populations and advances in biomedical technologies. At the same time, in the current economic climate, many Western countries are struggling to reduce public spending on all kinds of services, including healthcare. With this tension between tightening budgets and skyrocketing costs, many countries are seeking to identify ways of using Information Technology (IT) and Monitoring Technologies (MTs) to improve the efficiencies of HCSs while not reducing, or possibly even improving, the quality of healthcare and their delivery. Many experiments have been in progress since the 1990s. This paper has conducted a review evaluating such HCSs in terms of advantages and drawbacks. The objective of this review is to provide some illustrative publications and works and examples of Health Information Technology (HIT) systems to finally determine the place of biomedical MTs in the future HCS. We present the healthcare delivery system (HCDS) organization with roles of the different stakeholders, state initiatives in healthcare information delivery systems and the new relation between the hospital and the home though a new equilibrium. We mentioned the increasing role of telemedicine (TM), telecare (TLC) and telemonitoring (TLM) and expectations for monitoring the elderly. These expectations lead to preventive approaches based on monitoring technologies and pervasive healthcare $(\mathrm{PH})$ which made healthcare improvements and cost reductions possible. Finally, we show the challenges and opportunities of the hospital versus home healthcare delivery.
\end{abstract}

Index Terms-Monitoring technology, healthcare systems, health organizations, electronic medical records, information and communication technologies

\section{Introduction}

$\mathrm{T}$ His study focuses on Health Systems (HS) that have benefited from advances in and the use of Information and Communication Technology (ICT). The first important running evolution is the computerization of records such as the patients health record (HR) and the coordination of IT between all the actors in various health sectors [1]. The second important evolution with ICT is linked to the introduction of MTs. The third evolution is the development of a new computing platform called cloud computing, a service for users to access, pay for, and use a ubiquitous network on-demand. Cloud service is accessible to anyone, at anytime and anywhere, allowing the biomedical informatics community to take advantage of this new resource [2]. In these evolutions, the emergence of TM will certainly play an essential role in the medical dialogue and in the management of remote areas with isolated people [3]. This paper aims to make a review evaluating HCSs in terms of advantages and drawbacks and to provide some illustrative publications and works and examples of HIT systems. This review serves as a basis to discuss the trend towards a new equilibrium between clinical issues that are handled in the hospital, specialized medicine and healthcare at home. In our opinion, the technologies are mature, but the central issue as to the best way to implement them remains. Our study

These authors are with the University of Toulouse (Email: \{chan;campo;dbrulin;estive\}@laas.fr)

Manuscript received June 3, 2016; revised September 7 and December 20, 2016; accepted February 13, 2017. includes published peer-reviewed papers in the field of HIT between 1990 and 2015. Because this study is not an exhaustive presentation of the scientific literature in the field of HIT, only some representative HIT research platforms and projects from academia and industry are presented.

We begin this paper by presenting the HCDS organization with roles of the different stakeholders, some examples of state initiatives and the new relation between the hospital and the home though a new equilibrium. We mentioned the increasing role of TM, TLC and TLM and expectations for monitoring the elderly. These expectations lead to preventive approaches based on monitoring technologies and PH. Finally, we show the challenges and opportunities of the hospital versus home HCDS. Our analysis shows that change is underway; technologies are mature and their feasibility has already been validated. Their progression involves the establishment of complex multifunctional systems; a real approach in the way of system of systems is needed. We are particularly interested in how IT and MT can support changes in the organization of HCSs. Basically; we consider the demands related to elderly healthcare to serve as a guide and an impetus for the change mainly characterized by a needed convergence: the home and the hospital. We have examined and reviewed HCS hardware and software and have identified general considerations that should be incorporated in the future ideal HCS. This review is based on the various types of evolving technologies: IT, MT, home healthcare super- 
vision and HCS organization. To optimize the technical approach, we suggest distinguishing the several parts of these medical services: prevention, monitoring, urgency, and hospitalization, all of which would be affected by the introduction of IT and MT, each service in their own way. We show some illustrative examples of the literature to finally determine the place of biomedical MTs in the future HCS.

We describe the technical aspects through the instrumentation of the home and the patient and we conclude with a discussion of the evidence for the need to develop a new organization of HCS that brings the following changes:

-The clinical side must take into account the proximity of technology to prescribe their use.

-The technological side must take into account the human aspects of the HCS.

- New professions must be developed around the home to introduce and maintain home distributed devices.

- A new task distribution between actors is needed, in which the patient is the central subject, a partner and a stakeholder.

- Preventive actions must be developed and should be made more easily accessible with IT.

\section{Material and methods}

\subsection{Inclusion criteria for health information technology search}

1. TM interventions were categorized as devicebased measurements of vital signs or other parameters, IT-supported interactive systems, personal interventions (using telephone calls or videoconferencing between the patient and the healthcare provider or caregiver), or any combination [4]. TM interventions can be divided into three types: 1 ) diagnosis, monitoring and therapy, and rehabilitation in the case of measurements of vital signs using wearable devices (blood pressure (BP), body weight, and glucose monitors; pulse oximetry devices; $\mathrm{CO} 2$ gas sensors; galvanic skin response devices; electroencephalogram (EEG) devices; electrocardiogram (ECG) devices; electromyography (EMG) devices; ear sensors; and motion sensors), 2) interactive systems (in most cases IT-supported questionnaires), and 3) concepts technically supporting personal interaction between the healthcare provider and the patient (interventions using telephone, videoconferencing, and short messages) in the case of assisted living.

2. Transforming HCSs with IT is a strategy largely accepted since the development of ICT in the nineties. The motivations are two-fold: the quality of healthcare has been improved by medical staff thanks to betterprepared and more complete documentation on the patient, and systems for exchanging information between medical professionals have made delicate decisions possible for the patient. Patients can benefit from improved quality of diagnosis, follow-up care, and time management. For older people, technology-based TLC services have the potential to enhance and maintain the well-being and independence of a wide range of individuals who would otherwise be unable to live independently at home. These technologies also allow preventing or minimizing the effects of accidents at home (falls, fire, flooding, etc.). Promoting TLC is also part of a strategy to reduce the number of older people entering institutional care units and hospitals [5].

3. Electronic health records (EHRs) are a major factor when TM, telehealth (TLH), and home-based TLC applications are implemented [6]. The impact of EHRs is not only related to the amount of resources necessary to their implementation. The issues of their round-theclock (seven days a week, 24 hours a day, 365 days a year) accessibility and storage are of paramount importance, and their standards and formats are changing [7].

4. Most research projects in HIT are focused on platforms to support healthcare organization (HCO) systems [8]. HIT is a key effort in improving care delivery, reducing healthcare costs, and improving the quality of healthcare. Evidence from EHR use suggests that HIT will play an essential role in transforming primary care practices and chronic disease management [9]. Under the supervision of a center at a level such as a national, regional or inter-regional level, a platform may include many entities: hospitals, outpatient clinics, biomedical analysis laboratories, pharmacies, and physicians and nurses offices.

5. As regards HITs that access vital signs using wearable, portable and/or implantable systems, the issues of their safety, security, privacy, efficiency and acceptability should be studied.

\subsection{Inclusion criteria for study area search}

We included HIT platforms and systems in healthcare delivery, HIT review studies, and studies related to HCS design, implementation, socio-economic impact, privacy, security, safety, legal policy, ethics, use, cost and benefits, users needs, or acceptance. We were interested in finding papers that address the issues of patients or healthy people that have a likelihood of becoming sick. Particularly interesting in HIT are prevention issues rather than issues related to care.

\subsection{Search method and strategy}

This literature review did not have the aim of including an exhaustive search of scientific works and publications and is not a systematic review. Rather, the objective of this review is to provide some illustrative publications and works and examples of HIT systems. Our study includes published peer-reviewed papers in the field of HIT. Our search was limited to papers in reviews, journals, chapters of periodicals, and congress proceedings between 1990 and 2015. Some web sites describing systems, projects, or governmental or international institutions reports were included when the published scientific literature did not provide adequate information on the subject. Keyword searches were conducted in Scopus, Elsevier, IEEE explore, Springer, PubMed, and PubMedCentral and using a Google 
search engine.

\subsection{Results}

In our search, we tried to find papers, abstracts, and websites with the keywords listed in Table 1 . The keywords were used alone and/or in combination. The search results were screened for papers that gave a clear description of HCSs. Because of the large number of papers and abstracts retrieved, a decision was made to include only articles published after 1990. Because this study is not an exhaustive presentation of the scientific literature in the field of HIT, only some representative HIT research platforms and projects from academia and industry are presented.

TABLE 1: Keywords used in the papers research

\begin{tabular}{|c|c|c|}
\hline Assistive Technology & Hospital healthcare & Smart home \\
\hline E-health & Implantable device & $\begin{array}{l}\text { Smart wearable } \\
\text { system }\end{array}$ \\
\hline Economic analysis & $\begin{array}{l}\text { Information com- } \\
\text { munication } \\
\text { technology }\end{array}$ & Telecare \\
\hline Electronic patient record & In vitro device & Telehealthcare \\
\hline Electronic medical record & In vivo device & Telehomecare \\
\hline Home healthcare & Law & Telemedicine \\
\hline Healthcare & $\begin{array}{l}\text { Monitoring technol- } \\
\text { ogy }\end{array}$ & User acceptance \\
\hline Healthcare System & Portable device & User needs \\
\hline Healthcare technology & Robot & User privacy \\
\hline Home care & Robot companion & \\
\hline
\end{tabular}

The number of hits from the HIT search is shown in Table 2.

TABLE 2: Number of hits from search

\begin{tabular}{|c|c|c|c|}
\hline & Scopus & PubMed & $\begin{array}{l}\text { PubMed } \\
\text { Central }\end{array}$ \\
\hline Monitoring Technology & 91038 & 42052 & 114372 \\
\hline Chronic Disease & 817233 & 531720 & 634309 \\
\hline People Monitoring Technology & 3002 & 7962 & 43909 \\
\hline Healthcare Monitoring Technology & 2690 & 3254 & 33556 \\
\hline Healthcare System & 66553 & 859518 & 355261 \\
\hline Healthcare & 3131 & 4493 & 403749 \\
\hline Healthcare Technology (HT)smart & 19400 & 43774 & 111350 \\
\hline HT User acceptance & 266 & 240 & 3345 \\
\hline HT User Needs & 898 & 528 & 9271 \\
\hline HT User Privacy & 217 & 90 & 2539 \\
\hline HT Law & 414 & 3321 & 10713 \\
\hline HT Economic Analysis & 652smar & t4122 & 78666 \\
\hline E-health & 159787 & 114566 & 127903 \\
\hline E-health ICT & 1934 & 1613 & 25004 \\
\hline E-health System & 40991 & 21239 & 96248 \\
\hline EPR & 23503 & 23804 & 51798 \\
\hline EMR & 32073 & 21716 & 53281 \\
\hline E-health IT & & 29759 & 45842 \\
\hline E-health Home & 7311 & 3333 & 29688 \\
\hline E-health hospital & 21979 & 36688 & 63961 \\
\hline E-health Vital Sign & 326 & 1131 & 6480 \\
\hline E-health Elderly & 5701 & 23838 & 44821 \\
\hline E-health Smart Home & 153 & 48 & 1717 \\
\hline Smart Home & 6999 & 432 & 7501 \\
\hline Smart Wearable Sensor & 752 & 59 & 566 \\
\hline Telecare & 1022 & 2577 & 2577 \\
\hline Telehealthcare & 120 & 62 & 151 \\
\hline Telehomecare & 144 & 67 & 116 \\
\hline Telemedicine & 21859 & 18885 & 6670 \\
\hline Homehealthcare & 11041 & 40752 & 94501 \\
\hline Hospital Homehealthcare & 3624 & 13074 & 66969 \\
\hline Robot Companion & & 25 & 409 \\
\hline Robot healthcare & & 454 & 2661 \\
\hline
\end{tabular}

\section{From information technologies to monitoring technologies: The fundamental drivers of change in healthcare delivery}

The HCDS is an enormous organization. Multidisciplinary and multi-sector stakeholders intervene in this organization. To progress using IT in such a complex organization, it is necessary to decompose the global issues into subsets that are easier to manage and to coordinate the different entities as a system of systems. As shown in Fig. 1, EHRs are the heart of emerging HCDS organizations. The design of EHRs is important; EHRs contain administrative, clinical, and personal data. The real database must be immediately accessible and flawless in providing useful data in the context of multi-disciplinary issues. The computerization of HRs is underway. Effective use of HIT improves the quality of healthcare and reduces healthcare costs considerably, but the latest technological advances must be used to ensure the privacy and security of patient data through the use of EHRs [10].

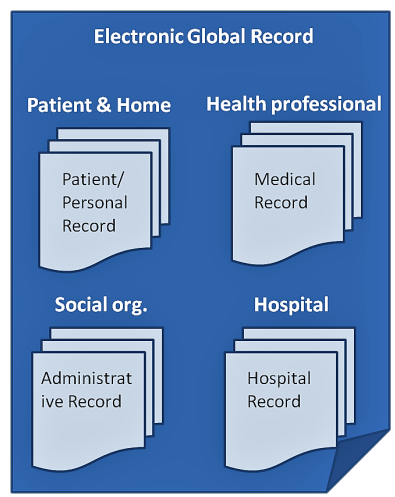

Fig. 1: Interconnection of EHRs concerning a patient

When data is available from any location, it becomes necessary to explore other forms of organization for HCSs. Efficient exchange of information between all actors is important for the enhancement of patient followup and for good medical practice. The introduction of ICT is supposed to result in more rigorous management and consequently in a cost decrease [11].

This penetration of ICT into HCSs is in progress in most countries. We are interested in new forms of organization that have arisen from this gradual computerization. The idea regarding expenses is to reduce the duration of hospital stays and to develop less invasive medical and surgical procedures. Regarding ICT, patient follow-up using either human or home devices has been developed in a clever manner so that the HCS is nonintrusive to the patient. One interesting aspect is the proximity between the care delivered at the hospital and the care delivered at home. Maintaining the elderly at home requires ensuring his or her remote monitoring (RM) using technology that we have called MT.

\subsection{Stakeholders: roles and tendencies in the process of HS/IT evolutions}

Advances in IT offer new ways to reduce labor and time costs and provide necessary knowledge and skill support. Healthcare delivery includes: diagnosing dis- 
ease; devising a treatment plan or dispensing therapy; educating patients; communicating with patients, family members, and other caregivers; and keeping or reporting data. A shared database of guidelines for the interfaces is therefore important to set up. All the actors should organize their own activity and at the same time work together in an overall network that should include home care. Legal frameworks still need to be set up to introduce TLM during the course of ordinary physician services to give private or state insurers the means to reimburse TLM-related fees. In the United States, teleradiology services are reimbursed, but teleradiology does not differ from traditional radiology because the radiologist rarely interacts with patients in person. The centers for Medicare \& Medicaid services limit reimbursement to TM services provided in rural areas, except for teleradiology and telepathology [12]. In European nations, certain TLM services, but not all, are reimbursed [13]. All the following actors have an active part in the changes in HS, each of them having different aims and points of view that have to be brought together and coordinated.

\subsubsection{Patient expectations}

Patients are empowered to take a more active role in their health management and prevention [14] [15]. The use of Internet medical sites may allow patients to learn more about their health conditions, to schedule appointments, to see their laboratory analysis results, and to e-mail and have online discussions with doctors. Electronic databases allow follow-up of patients susceptible to a particular disease; when precursory symptoms appear or new information becomes available, physicians can intervene [16]. Disease prevention and health promotion should be considered to make people live better autonomously. Patients should be involved in the building and availability of their patient record (PR). Verified and aggregated patient record data (PRD) would contribute to building a global record (GR). Access to personal data through the use of the Internet, an electronic medical database, or e-mail should be accomplished in a secure manner. The patients evaluation will be accessed during admission to the hospital, as well as the diagnosis of the patients condition, and the handling of the patient by the HCS. Patients also have many expectations of home healthcare. The technology should ensure security, confidentiality, and privacy in all circumstances; TLH can provide services to overcome patient isolation while preserving the patients independence. For the elderly and disabled, TLH may reduce the need for travel, but there is a real danger of isolation for these groups; at the same time, legal issues are not yet in place in many or most developed countries [17] [18].

\subsubsection{Social organizations}

Social organizations are driven by national governments or health insurance organizations funded by the employers (in the case of a private company). Their main expectations are to manage healthcare more efficiently in a system in which patients assume an important part of these costs, while the remainder is paid by the collective. In France, all healthcare expenses are managed through a platform called Scurit Sociale [19].

\subsubsection{Hospitals}

Hospitals provide advanced healthcare that involves heavy investments and costly hospital stays. A more proactive admission process and management of patients, as well as a hospital/home follow-up system should be instituted. In-patient costs constitute one of the items being cut from hospital budgets. The hospital is probably the best place to manage medical PRs. In Europe, some countries such as Denmark are promoting a reduced average length of stay (ALOS) while maintaining or enhancing the quality of care. Strategic reductions in hospital bed numbers alongside the development of community care services can shorten the ALOS. Denmark promotes the use of less invasive surgical procedures, changes in hospital payment infrastructure, the expansion of early hospital discharge procedures that allow patients to return to their home to receive follow-up care, and support for hospitals to enhance the coordination of care across diagnostic and treatment pathways [20] [21].

\subsubsection{Health industry}

The health industry could benefit from advances in technology. The potential for market extension is unlimited. The technical HS must spread from hospitals to rural areas. Legal and policy issues should be addressed by administrations and public authorities. Some countries have already allowed physicians and hospitals to do business with patients in other countries [22] [23].

\subsubsection{Providers}

Providers (general practitioners, physicians or nurses) will benefit from IT. Innovations in healthcare are new ways of helping medical professionals work smarter, faster, better and more cost effectively while providing high quality care [24]. Providers will become natural interfaces between patients and all the other actors; they will also become the builder of PRs. Electronic Medical Records (EMRs) allow easier communications between medical professionals who are caring for the same patient and enable monitoring of the patient. Electronic medical decision support systems allow clinicians to enter a patients symptoms, receive a probable diagnosis, and more quickly obtain the correct diagnosis. Effective treatment strategies may be designed using point-ofcare databases including the most current evidencebased techniques for dealing with various diseases. Electronic prescriptions can lower the incidence of mistakes resulting from illegible handwritten prescriptions, incorrect doses or drugs interactions. Possible solutions to the issues of practitioner shortages in rural areas include changing the medical education system so that it will train more practitioners choosing to practice 
in rural areas and the use of telemedicine to counter the effects of the geographic misdistribution of health professionals [25].

\subsubsection{Pharmaceutical suppliers}

They have access to PRs. They receive and carry out medical prescriptions, give advice on dosages, and collect unused medicines. They would be involved in managing rented medical materials and devices or medical devices bought by patients. They suggest evaluations and improvements.

\subsubsection{Biological analysis stakeholders}

They have to look at the levels of specific substances and enzymes that are produced by chemical reactions in the human body. With the advent of the technological systems, these stakeholders may have an important role in organizing their work in the support of efforts to manage patient illness. Metabolic disorders are often the result of a missing or non-functional enzyme. As a result, several harmful changes in body biochemistry can occur.

\subsubsection{Home healthcare network}

The strengthening of home healthcare is a potentially strong emerging option. This option has the possibility of reducing costs by shortening hospital stays and maintaining care for the elderly, disabled, and those suffering chronic diseases at home. Home healthcare stakeholders (such as associations, caregivers, and families) will go on to manage their services at home (or in a clinic) under medical supervision. They will benefit from IT (e.g., access to PRs) and should be able to better find and organize their fieldwork.

\subsection{Examples of potential changes in hospitals}

Clinical IT in hospitals [26] can be divided into four principal areas: notes and records, test results, order entry, and decision support. Data in each of these domains are currently managed through paper-based systems. To the degree that these functions are automated, the hospital is paperless. There is a relationship between a hospitals degree of being paperless and in-patient outcomes. IT holds great promise as a tool to improve hospital medicine. In certain conditions, greater automation of a hospitals information system may be associated with reductions in mortality, complications, and costs, suggesting that ITs that are properly designed and executed around clinical workflows could meet that promise.

Electronic Healthcare (e-health) involves a variety of ITs ranging from EHRs to a national health information network to remote patient monitoring. It is necessary to distinguish between organizational processes (e.g. medical order entry and results reporting) and the medical treatment process (e.g., diagnostic and therapeutic procedures to be carried out for a particular patient). The support for organizational processes is closely related to application integration. The hospital information system is characterized by different departmental systems, which have to be optimized for supporting different medical disciplines (e.g. radiology, cardiology or pathology), not for cross-departmental processes. Standards for data and message interchanges in healthcare have been developed (e.g., HL7 and DICOM). The best example of a standard that has been developed is Integrating the Healthcare Enterprise [27] (IHE). The core integration profile of IHE is called scheduled workflow, which establishes a seamless flow of information in an image encounter (e.g. to generate an X-ray for a patient) by specifying the actors and transactions involved in the process of image acquisition. By fixing the workflow steps and the corresponding transactions, IHE ensures the consistency of patient data from registration through ordering, scheduling, imaging acquisition, storage, and viewing. The diagnostic-therapeutic cycle is a medical treatment process that includes observation, reasoning, and action. The observation stage starts with the patient history and proceeds with diagnostic procedures based on available information.

Using EHRs [28] allows storing data electronically and exchanging data with providers practicing in other settings. There are four key categories of system functionalities: clinical documentation, test and imaging results, computerized provider order entry (CPOE) and decision support. The benefits include reduced medication error rates, which reduces the frequency of adverse drug events, avoids redundant laboratory and radiology tests, and improves efficiency in moving from manual to electronic data exchange.

For individuals, a face-to-face consultation in the doctors office or during a hospital stay necessitates medical personnel searching through paper charts and records to administer care [29]. Progress in IT in hospitals and healthcare settings that allows information to be readily communicated and shared among healthcare providers improves the quality of care and helps to control healthcare costs over the long term. The merits, challenges and implementation of HIT will require considerable cost incursion in the near future and in the short term. In [29], the authors claim that in the United States, $17 \%$ of physicians practicing in an outpatient setting had at least a basic EHR, with only $4 \%$ using a fully functional system.

Sharing of personal EHRs by medical professionals can increase administrative efficiency and reduce healthcare costs by eliminating unnecessary duplication of medical analyses and, most importantly, by eliminating medical errors. According to the authors [30], the United States lags behind Europe in sharing personal EHRs. Most European countries have a single (public) payer that has the ability to subsidize, as well as to exert pressure, if required, for professionals to share [31]. The risk of sensitive health data leaking out and being misused is reduced when there is less need to transmit information across providers and platforms. 


\subsection{Examples of state initiatives in healthcare informa- tion delivery systems}

- In the United States [29], for most Americans, a trip to the physicians office or a hospital stay necessitates medical personnel searching through paper charts and records to administer care. This remains the status quo, despite the increasingly large role that IT plays in other aspects of their business and personal lives. Several changes in organizational structure and state/federal policies must be implemented to address these challenges: technical and implementation support, system certification, decision support, empirical research on organizational complements, and, regarding Health Information Exchange (HIE) value-matched funding, payment reform. As part of the economic stimulus package enacted in February 2009, the United States government has allocated approximately $\$ 19$ billion a year in funding for programs to help healthcare providers implement EHRs. These programs have the aim of encouraging the adoption of IT-enabled systems and processes that allow computerization of physician orders to automate dispensing of drugs and to enable digital storage of PRs. The objective is to enhance the quality of care delivered by ensuring timely access to PRs, thus eliminating errors or duplicative tests and yielding significant savings. The federal government will cut Medicare reimbursements to healthcare providers that do not attain the target goals specified under the meaningful use guidelines related to EHR adoption by 2005. In [32], the authors demonstrate the cost-quality tradeoff associated with the use of IT hospitals. They found important implications for policy makers as they provide empirical evidence on the effectiveness of measuring IT-enabled healthcare quality. Their results show that application of health IT, without developing a better understanding of treatments that work and those that do not, may be counter-productive and lead to cost inflation, as proponents of comparative effectiveness research have observed [33]. It is important to distinguish between the different types of IT applications when considering their impact on the quality of the healthcare process. There is a differential impact of IT applications on process quality, and there are significant differences in the impact of clinical and administrative systems on healthcare quality and costs [24]. Future trends in healthcare related to information and databases will help healthcare executives and practitioners establish the groundwork for fundamental changes within HCOs; the inclusion of a wide range of patient demographic, clinical and medication information; and the development of integrated, accessible EHRs [34]. These trends will allow doctors to communicate easily and quickly with patients and staff members; they will also enable consumers to be aware about healthcare through online healthcare forums and other health information systems.

- The northern area of France [35], the Sant Social network is now available. It takes into account a favorable environment with the context of increasing computerization of medical records in medical offices, the development of hospital information systems, the use of medical smart cards, and the generalization of the communication of digital information through new IT. The platform RITHME will allow asynchronous communication between the participants of a medical sector, answering to the needs and expectations of physicians working in private and public areas. This platform gathers 40 family physicians, two hospitals, and three laboratories in a given area and will generalize its offer. The RITHME platform provides to medical professionals the following services: a real-time communication system; all documents such as texts, laboratory medical exams, and imaging; area for exchange between the city and hospital; access to information (Web servers) and training services. These services allow benefits for both public (hospital) and private (family) physicians: travel and time savings, quick transmission for urgent and sensitive information, presentation of documents with quality and clearness, independence from the telephone, reliability, security and speed. An intermediation platform has been set up between all physicians working in each area. It is currently and routinely used to secure data exchanges [36].

- In Japan [37], a number of issues are challenging society, such as caring for an increasing elder population (which negatively impacts the sustainability of the insurance structure) and dealing with strained medical resources: The costs for people aged 65 and older are three to five times greater than for people younger than 65 in Japan. The elderly are also exacerbating resource shortages in acute care facilities, with their extended lengths of stay nearly three times as much as in other countries such as the United States. The elderly tend to use hospitals and emergency rooms as clinics for chronic diseases care that could be managed in less costly care environments such as nursing homes, community clinics or even private homes, if equipped with sufficient technological infrastructures. The shortage of medical personnel is a reality particularly in rural areas. For organizations such as the Insurance Claims Review \& Reimbursement Services, electronic claims (e-claims or on-line claims), as a type of HIT, are poised to help decrease the costs associated with gathering patient data from the various healthcare entities servicing patients across a region, but adoption has been low (less than $20 \%$ of all healthcare facilities). The bureaucracy often restricts information sharing between HCOs in the name of patient privacy protection. The autonomy of each faction has also in the past precluded cooperation between medical professionals within the same communities, resulting in a lack of a concerted effort to improve care with a patient-centric focus. Promoting the use of IT in the mid to late 1990s, these primitive initiatives focused on exchange of clinical observation data and radiological data between hospitals, laboratories, and clinics within a community rather than extending across an area. These exchanges included the patients own record of care retained on a diskette, the data on which patients provided permission to view during referral 
visits. From 2003 to 2007, the Japanese government allocated 2.6 billion yen for 26 areas. Hospitals were the primary participants. Only a few of them are still surviving. The initiatives were regarded as experimental, and at the time there is no grand design for widespread IT adoption. From April 2009 to 2013, the Japanese government allocated 235 billion yen, of which 250 million yen are to be spent directly on the improvement of HIT systems.

- The Lombardy Region of Italy [38] has almost 10 million citizens and has set up the Regional Social and Healthcare Information System connecting all the healthcare providers within the region and giving full access to clinical and health-related documents independently from the HCO that generated the document. The HCS has adopted the Health Level 7 (HL7) standard within single hospitals under political and operative pressure and provides a technological infrastructure for data sharing based on interoperability specifications recognized at the regional level for messages transmitted from healthcare providers to the central domain. Integrating the Healthcare Enterprise (IHE) integration profiles that comply with HL7 standards are used within hospitals for message exchange and for the definition of integration scenarios. The IHE Patient Administration Management (PAM) profile with its different workflows is adopted for patient management, whereas the Scheduled Workflow (SWF), the Laboratory Testing Workflow (LTW), and the Ambulatory Testing Workflow (ATW) are used for order management. The HCS at present manages 4,700,000 pharmacological eprescriptions and 1,700,000 e-prescriptions for laboratory exams per month. Every month, it creates 490,000 laboratory medical reports, 180,000 radiology medical reports, 180,000 first aid medical reports, and 58,000 discharges summaries. According to their creators, the Lombardy Region Healthcare Information System is a fully inter-operable social HCS connecting patients, healthcare providers, HCOs, and healthcare professionals in a large and heterogeneous area through the implementation of international health standards.

- In New Zealand (NZ) [39], the shifts from hospitalcentered healthcare to patient-centered healthcare and from cure to prevention have implied the introduction of new innovations that could assist healthcare providers with efficient services to patients and health clients [40]. A TM network has been set up where distant and dispersed patients are brought closer to their medical providers through the means of IT. TM can assist in reaching out to rural patients [41] and to areas where patient volume for some services are limited [42]. It can assist in implementing administrative and clinical meetings, in providing different health awareness courses to users (such as information on smoking cessation), in delivering training courses to physicians, nurses, and other medical professionals. Health Waikato (HW) provides services to 330,000 people living in the Waikato district of the Central North Island of New Zealand. It delivers a range of health services to lo- cal and rural communities through one main specialty hospital and six rural hospitals. Three TMVC-ISDNs (Telemedicine Video Conferencing-Integrated System Digital Networks) were leased and operated by a single specialist physician and a number of medical officers. The rural hospital serves 10,000 people, does not offer surgical services, and instead employs specialist physicians and medical practitioners. Another TMVC unit is installed in the main hospital for educational purposes. HW was among the early adopters that explored the potential of TM for medical care in the early nineties. The TMVC system allows instant and continuous access to remote and rural patients, which benefits the patients.

\subsection{Towards a new equilibrium in the hospital and the home}

We have illustrated some gradual computerization trends in the management and organization of HCSs in different countries. The PR is at the heart of this evolution to maximize care and avoid service duplications during follow-up. These changes are on the way, and their success is necessary to allow a new equilibrium in the hospital and the home. Maintaining people at home is becoming a possible complement to hospital care in the era of computerized data exchanges with hospitals, improved hospital/home mobility, and the establishment of medical RM at home. Care for the elderly at home may become the prescribed medical care that supposes a structure allowing follow-up, i.e., devices embedded at home or worn by patients that enable them to be monitored for safety. Thanks to data gathering and processing using home-embedded systems, adverse events warnings have been made possible. At the same time, the patient remains in his or her usual well-being environment at home and may benefit from family care. All convalescent patients and older people can benefit from this in-home support connected to the hospital.

Two types of patients are of concern:

- Frail people: for them, it is necessary to develop a monitoring system able to detect and anticipate the risk that they become dependent,

- Dependent people: for them, the risks are dangerous, and it is worth establishing a 24-hour-a-day monitoring system.

For these two types of patients, technological developments are necessary, and new HCOs have to be put in place to interconnect hospital expertise and the physicians; sharing PRs and exploiting TLH will play an essential role as important as the local actors are close to the patient. Caring for patients in their home also implies the need to develop measurement and monitoring technologies. This is a new field for research and applications. We are personally interested in the impact of the monitoring technologies [43] that are already available to help the elderly remain at home and thereby benefit from a familiar environment. Healthcare follow-up data allow the automatic building of a personal database containing information about the patients health status 
and any changes to it throughout the patients life. Such a database allows for the possibility of monitoring and following up on the frail elderly living at home instead of in an institution. Note that healthcare innovation requires educating people on how to adopt a healthy lifestyle [44]. Some examples of developments demonstrate the innovations of home care [45].

\subsubsection{The increasing role of telemedicine, telecare and telemonitoring}

The growing number of old people causes an increase in the incidence of chronic diseases and disability and will deeply impact HCSs. In this context, TM and TLC will necessarily take a more important role. Innovative technologies and medical progress allow following-up on those people who need help controlling symptoms of diseases (such as diabetes mellitus, heart failure, cancer, chronic obstructive pulmonary disease, hypertension, cardiac disease, and angina) or after an acute phase of a disease (such as stroke, coronary artery bypass, and acute myocardial infection). People living in medically underserved areas could also benefit from monitoring healthcare services that overcome distances and alleviate gaps in their living environment. People could remain in their own home for as long as possible instead of going to an institution. Despite some barriers and drawbacks [46], telemedicine and TLC have considerable potential for supporting older people who suffer from chronic illness or disability and desire to be independent and autonomous [47]. In parallel, smart devices, systems and concepts have to be developed to satisfy their needs and handicaps.

Another use for TM and TLC is for populations living far from medical and clinic centers in many rural and remote areas. The spatial distribution of healthcare stakeholders is sparse in these regions of low population density. Providing healthcare near the patients homes is difficult. TM is able to bring solutions for diagnosis, therapy, and rehabilitation. TM services can be divided into three types: device-based assessment of vital signs or other parameters, IT-supported interactive systems or individual interventions [4]. TM [48] provides education to improve self-management, enables information transfer, and facilitates contact with health providers. Some examples are instructive:

- Heart failure (HF) is an increasing epidemic disease with the number of hospitalizations constantly growing. TLM is viewed as a means to collect physiological data, such as body weight, heart rate, arterial BP and ECG data; these data are collected by wearable devices that transmit these readings remotely by means of a telephone line, a mobile phone or a computer to a center where they can be stored, reviewed and analyzed by the research team. TLM and structured telephone support have the potential to deliver specialized management to patients with chronic heart failure, and both appear to be interventions that are effective in improving outcomes. But their efficacy is still to be proven [49].

- In terms of cancer, research is underway on the use of TM as a useful tool both in distant diagnosis and confirmation of previously made uncertain diagnoses. The technique can be employed not only in less fortunate geographical regions where skilled specialists are not available, but also in technologically advanced areas where TM allows a multi-disciplinary approach in cases of uncertain and complex diagnoses. Re-evaluation of radiological data or histological specimens through TM leads to reductions diagnosis costs and time and increased sensitivity provided that senior and experienced trainees are involved as recommended. The study points out that cost-benefit and cost efficacy data are lacking, in particular, those comparing complex models (use of high technology) versus simple models (simple scheduled telephone follow-ups plus calls from patients to integrate conventional visits) [50].

- In the case of stroke, TM allows general neurological assessment, primary and secondary prevention and rehabilitation, notification and response of services; acute, sub-acute, hyper-acute and emergency phase stroke treatment. Management of intra-cerebral hemorrhage is improved by selected triage to centers with neurosurgical capabilities. More rapid diagnosis of the underlying mechanism of ischemic stroke may lead to more rapid institution of secondary prevention therapy. TM in this case is a technology that may enable the delivery of previously validated interventions. The technologies used consist of videoconferencing applications for delivering multi factorial, in-home rehabilitation interventions for community-dwelling adults who were recently prescribed a mobility aid [51].

- Prevalence surveys have found that the BP control rate among patients with hypertension is less than $25 \%$. TM has been shown to be effective in lowering BP. However, major design flaws and high operating costs have hindered its adoption by specialists and patients. For patients, mobile phones, which most people use to some extent in everyday life, appeared to be an acceptable alternative for gathering, messaging and receiving alerts, as long as it did not involve operations beyond normal use. ICT improves the management of hypertension: the system longitudinally records the results from BP monitoring. It is programmed to deliver adherence reminders when the monitoring schedule is not being followed or clinical alerts when hypertension is poorly controlled, send coaching messages to patients, and provide reports in tabular, graphic and summary formats to both patients and healthcare providers [52].

- Patients problems with asthma medication use may include underuse of controller medications, overuse of rescue medications, and improper inhaler technique. The TLH interventions consist of telephone, video and Internet-based models of care. A study by McLean et al. [53] showed that a meta-analysis did not bring a clinically significant improvement in patients quality of life, and there was no significant change in the number of visits to the emergency department over a period of 12 months. There was a reduction in the number of patients admitted to hospitals one or more times over 
a period of 12 months. According to their study, further research is required to clarify the cost-effectiveness of care models based on TLH.

Low to very low-quality evidence shows nonsignificant effects or conflicting effects for all outcomes examined when comparing home TLM to usual care. The economic impact of home TLM is still uncertain and requires further study. Home TLM is largely dependent on local IT, infrastructure, and personnel, and thus the generalization of external findings may be low [54].

\subsubsection{Expectations for monitoring the elderly}

Monitoring the elderly is a priority because nations throughout the world are now experiencing growth in the number of older people. In 2012, the world population was 7.2 billion; in mid-2013, the world population was projected to increase by almost one billion people, reaching 8.1 billion in 2025 and to further increase to 9.6 billion in 2050 and 10.9 billion by 2100 . The percentage of people aged 60 years or over increased from 9.2\% of the general population in 1990 to $11.7 \%$ in 2013 and is expected to reach $21.1 \%$ in 2050 . The number of people aged 60 years or over is expected to more than double, from 841 million people in 2013 to more than 2 billion in 2050. Globally, the number of persons aged 60 or over is expected to more than triple by 2100; the number of those aged 80 or over is expected to increase almost seven-fold by 2100 , increasing from 120 million in 2013 to 392 million in 2050 and 830 million in 2100. The aging of the population is unprecedented. By 2050, the number of elderly in the world will exceed the number of children for the first time. It is a universal lasting phenomenon; the trends are not ready to reverse. The world population of the elderly increases $2 \%$ each year, more rapidly than the population in general. This rapid increase in the number of elderly will require new solutions from most of the countrys social, economic and HCSs [55].

Patients expect to live longer and in good health. This expectation means that there are prevention issues linked to the concept of frailty [56] [57]. For the elderly becoming more and more dependent, home care could be a good option made possible through the use of MT at home: - Smart home monitoring of gait velocity with passive pyroelectric infrared (PIR) sensors has been shown to be an effective method of continuously and unobtrusively assessing this important predictor of cognitive function and mobility in real time [58]. Slow gait speed and low physical activity or exercise seem to be the most powerful predictors of disability in performing the activities of daily living (ADLs), followed by weight loss, loss of lower extremity functions, loss of balance, loss of muscle strength and other indicators. Monitoring physical frailty indicators in community-dwelling elderly [59] may be useful in identifying elderly that could benefit from an intervention program aimed at disability prevention. The frail elderly have a higher risk of ADL disability compared to non-frail elderly. Such an intervention could partly relieve the burden that frailty places on individuals, care providers and HCSs as a whole.

- Smart home-based health behavioral monitoring [60] is an approach based on probability that identifies activities in a smart space from sensor data while the activity is being performed. By quantifying probability anomalies in the received sensor data, a metric of how an activity is performed can be computed.

- In the HOMECARE project [61], assistance is set up at home using infrared (IR) sensors and high frequency tags. The patient wears a tag in his back. Three functions are implemented: identification, location and fall detection. Outside, beyond the roughly ten meter perimeter covered by high frequency tags, GPS is used to follow the outside trajectories of the patient [62].

The global trend from these examples will be to combine all the personal measurements, those that are filtered and synthesized, with patient EHRs. An important issue is to process warnings; it is vital to design systems able to be in permanent contact with the patient and to initiate urgent processes in the case of a dangerous event. A local capability could be set up to analyze the data collected to diagnose the disease. A medical monitoring system could then be used for advice and referrals to other services, such as the regular physician, emergency services, preventative services, and hospital services. Fig. 2 shows the process for following up on frail people.

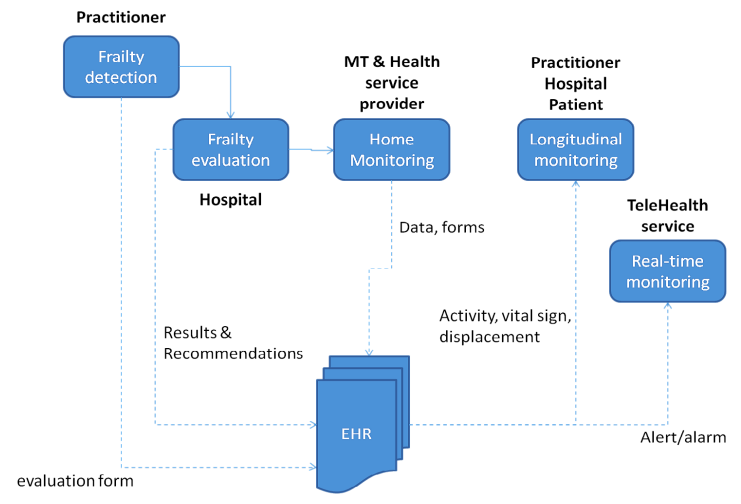

Fig. 2: Organization for the monitoring of frail people

\subsection{Preventive approaches}

Preventive approaches are relevant for individuals defined as frail, which means that they are independent but likely suffering from or experiencing the first signs of change due to chronic diseases linked to aging [63]. Monitoring oriented for prevention will increase the reactivity of patients and physicians toward changes in health and will minimize danger. The system has to be patient-centered; the patient remains in his/her home and is able to receive reliable healthcare services. The stakeholders are the hospital, the regular physician, and those involved in in-home nursing healthcare delivery, 24-hour-a-day monitoring, intervention, and technical maintenance. The aim is to contribute to:

- increasing disease and injury prevention;

- changing social and environmental exposures that 
can cause diseases and injuries; and

- providing healthcare counseling and vital signs monitoring.

In-home visits [64] aim at preventing falls and impairments among the elderly living in the community [65]. PH changes in the healthcare delivery model include changes from doctor-centric to patient-centric, from acute-reactive to continuous preventive, and from sampling to monitoring [32]. $\mathrm{PH}$ should maintain wellness instead of managing illness [66].

Many patients are now ready, willing, and able to take a more active role in their own care and the care of others suffering from diseases [67]. Clinicians may help patients obtain services such as counseling, storytelling, support, information sharing, and empowerment-based training that had been a routine part of the typical office visit. These services can be obtained by referring them to online patient networks. Practicing patient-centered healthcare means delivering services to fit the preferences and needs of patients [68]. Patients may have discussions with doctors via the Internet without going to the doctors office and may also receive results of laboratory analyses, reminders, and physicians reports. In his or her home, doctors and other stakeholders help patients prevent illness, detect diseases earlier, manage chronic and episodic diseases, and coordinate health services with other specialists. The patient may be monitored for his or her activities or mobility under the control of a healthcare center. According to [24], HCS in the United States will move toward an outcomebased style of management. Healthcare executives and practitioners will take actions that have worked in the past and make them more effective. They will move toward a medical practice that will be more of a science and less of a craft. Practitioners are trying harder to prevent the occurrences of diseases. This is called evidencebased medical practice, which requires accumulation of patients medical records electronically.

\section{Monitoring technologies and pervasive healthcare}

We call MTs all the devices and systems distributed in buildings, homes, or generally in the environment (Internet connected objects), or those worn by people, that can be used to prevent, detect or monitor. More and more people use a tablet computer in their daily life. According to Insee, among 65 million inhabitants in France 2010 [69], 69.7\% have a PC including a portable system. Twenty million people have access to the Internet, and 42.3 million are users of the Web. With the growing availability of miniature, autonomous, and wireless sensors, it is easier to collect the information needed to implement home care services. Passive and active tags are increasingly used; these tags are implemented in an object, device, machine, production line or individual body. They are smart wireless minichips that can sense and act by data emission or transmission. Mobile phones are common systems that are being used by more and more people. They are become smart systems that establish a permanent link between ones home and the outdoors, allowing interactions and interconnections between various actors who are either monitoring or being monitored and providing a new way to assess the health of individuals including elderly people [70].

\subsection{Monitoring technologies in smart homes}

The aim is mainly to enable the elderly to remain in familiar surroundings as they age, not only to enhance their quality of living but also to lengthen their life. Since the early eighties, a great number of smart homes have been implemented and have been based on analyzing individual mobility and activities in the home:

- The first type of smart home principally studies the mobility of people in their home using IR sensors. Only one individual can be observed, and these observations are sometimes combined with actions taken by the resident. Many algorithms can be used to deduce mobility, such as reinforcement learning [71], the LeZi method (a probabilistic model that predicts the inhabitants typical path segments), and a triangulation method to provide the subjects location in his house. In this last case, a high-precision ultrasonic tracking system is used, the resident wears two beacons, and a smart phone is attached to his hand. Prosafe [72] is a monitoring system that locates and detects elderly falls based on IR sensors and a criterion of abnormal immobility in an area. Smart floor sensors sense the residents footsteps, which allow the home to build a model based on the users habits and behavior.

- The second type of smart home recognizes and tracks activities that people normally perform as part of their daily routine. The aim is to establish an automated approach to mobility tracking linked to frequent activities that naturally occur in an individuals routine. The tracking of occurrence of regular activities enables the monitoring of functional health and the detection of changes in an individuals patterns and lifestyle [73]. Unsupervised methods of discovering and tracking ADLs first discover activity patterns and then use a clustering step to group discovered patterns into activity definitions [74]. Passive sensors are used. The sensors used are motion sensors positioned on the ceiling, sensors to provide ambient temperature readings, and custombuilt analog sensors to provide readings from hot water, cold water, and stove burner use. Voice-over internet protocol (VoIP) devices capture phone usage, contact switch sensors monitor the open/close status of doors and cabinets, and pressure sensors monitor usage of key items such as medicine containers, cooking pots, and phone books. Five ADLs have been discovered and classified: phone use, hand washing, meal preparation, eating and medication use, and cleaning [75].

Activities can also be detected through a key object present in the environment. Hamid et al. use a low-level vision system to discover activities such as household kitchen use to deduce peoples health as they age [74]. 
Another example is a sensing system that uses a video camera and computer vision to track the positions of the users hands and the objects that are relevant to activity completion (e.g., soap and a towel). The system aims to help caregivers assist people suffering from dementia to complete activities they have forgotten how to do [76].

The house of the future proposes a smart services delivery system that conducts qualitative and quantitative studies on the relationships between environmental factors and the behavior of the subject. The sensors are fitted onto pieces of furniture, kitchen and bathroom appliances, and the washing machine. Using a contextaware experience sampling tool, pattern recognition, and classification algorithms, the user can label and recognize his or her own activities.

- The third type of smart home directly assesses the health conditions of residents by evaluating their vital signals either by health sensors fitted onto pieces of furniture, electrical and/or household appliances or by sensors worn by the users themselves. A smart home with a bedroom, a bathroom, and a toilet equipped with fully automated medical devices and a computer terminal for automatic data collection and transfer to a main computer allows assessment of physiological parameters (ECG) while an individual is taking his or her bath, lying in bed (time spent in bed, duration of sleep, onset of sleep, and waking time), or using the toilet. The profile of temperature changes while the resident is in bed allows the recognition of changes in posture and body movements [77].

Another example of a smart home is one that is equipped with devices fitted into the bed with an airfilled mat, a single unit and a bridge unit that handles the connections when a subject lies on the mat. The system enables measurement of heartbeats and respiratory movements that cause perturbations in air pressure. Al-Qirim [39] describes smart homes equipped with devices fitted either in the house (in the ceiling, floor, etc.), or in pieces of furniture (bed, chair etc.) able to measure vital parameters (breathing sounds, posture, body movements, etc.). Using medical equipment, it is possible to detect lung capacity, blood sugar, BP, mean arterial pressure (systolic and diastolic), pulse arrhythmia, body weight, temperature and fat.

\subsection{Wearable systems}

People have benefited since the eighties from assistance services using wearable devices. Miniature transmitters can be worn around the neck or wrist or carried in a pocket, allowing an individual to signal that they are in danger and/or request help by pressing a button. A new generation of wearable help devices and systems has appeared that enables people to be rescued in dangerous situations in which they are unable to ask for help (such as with stroke and unconscious states) [78]. Healthcare innovators are creating drugs and diagnostics [79] for diseases and disabilities and are developing small, implantable, accurately sensitive technologies that can enable sick people to be monitored and perhaps improve their health status. For example, a microchip embedded in an ingestible pill may provide an internal and continuous monitoring of the status important markers status such as glucose for diabetics. Its signals can be picked up by sensors embedded in a band-aid. The sensors transmit the readings to a mobile phone, which conveys advice to the patient on the basis of the complete glucose records and other data it contains. A diabetic may be notified to take insulin. Such technologies hold the promise of not only improving care, but also of reducing healthcare costs by lessening the need for a provider-to-patient interface and by accelerating care delivery, thus reducing the severity of illness. These systems are conceived to monitor individual indoor, outdoor and $24 \mathrm{~h}$ a day health conditions. Smart wearable systems (SWSs) include a wide range of wearable or implantable devices, from sensors, actuators, smart fabrics, wireless localization systems (GPS), mobile phones, mobile mini computers, personal digital assistants (PDAs), tablets, power supplies, wireless communication networks (WCNs), processing units, multimedia devices, user interfaces, software and algorithms for data collection, processing, control, and decision support. SWSs are used to assist patients in their own home and outdoors according to their medical needs and in accordance with preventive medicine protocols. The monitoring system is wirelessly connected to a help center where the measured parameters are continuously or intermittently transmitted. The center can provide assistance when the patient situation requires more attention. The ADLs or movements of elderly individuals can be monitored, and when changes in their life habits suddenly appear, such as a decrease in ADLs, social activities, motion, or appetite, or a propensity to remain at home; all these dangerous life conditions can be measured while analyzing the transmitted data. Wearable devices can take different forms such as:

- A smart cloth equipped with all sorts of sensors, actuators, multimedia devices, and power supplies. Vital signs can be assessed by sensors, actuators, and medical devices directly implemented in the fabric. Aside from cloths and/or vests, there are other items that incorporate smart sensors and actuators that are able to collect health-related data: backpacks, glasses, arm bands, shoes, jewelry, watches, etc. A sort of second skin has been developed that is capable of pressure readings using pressure-sensing materials associated with miniaturized electronic devices. The electronic skin uses a thin single-crystal silicon material that has superior flexibility and mobility properties. The system can be simply mounted onto or peeled off natural skin like bandage tape. Using this electronic skin, vital signs from the brain, heart, and skeletal muscles similar to those that can be detected using bulky electrodes and hardware can be detected. Other forms of physiological parameters can also be collected using this skin [80].

- Microfluidic or other micro-fabricated devices that 
are able to detect a wide variety of biochemical compounds in vivo such as glucose, cholesterol, lactate, urea, minerals (such as sodium, potassium, calcium, and magnesium), metals in trace quantities (such as zinc, copper, iron, nickel, lead, and chromium), alcohol, vitamins, proteins, oil, oxygen, etc. Living organ tissue can be analyzed in vivo and biopsies can be practiced using very sophisticated devices, medical instruments and wireless data transmission. Micro-electromechanical systems (MEMS) devices, including microreservoir drug depots, micro pumps, valves, and sensors, have been developed for the delivery of microgram amounts of drugs [81]. A microchip for drug delivery is capable of releasing drugs by opening various reservoirs on command. Fully integrated smart MEMS-based devices could replace entire biological systems and be responsive for delivering the right stimulus, such as a drug, a biochemical compound, or an electrical impulse at the right time [82]. Capsule endoscopes equipped with miniaturized video cameras represent a new appealing alternative to traditional techniques. Active locomotion devices could enable capsule endoscopy to be performed in a totally controlled manner. Capsule endoscopy offers new capabilities for screening, diagnostic, and therapeutic procedures [83].

- The era of replacing a defective human organ by an implantable system is underway. An artificial heart that is a prosthesis combined with electronic devices has been developed by a French company named Carmat [84]. Another human organ that has undergone intensive medical research is the kidney. The automated wearable artificial kidney (AWAK) enables people to avoid enduring dialysis several times per week in a dedicated center [85]. As with dialysis, the AWAK cleanses the patients blood of uremic waste metabolites, and normalizes fluid, electrolyte, and acid/base balance. The battery-operated pump and hemofilter filter the blood. In the native kidney, this function is achieved by the glomerulus, and the heart provides the energy for filtration [86] [87].

\subsection{The emerging role of assistance robotics}

Three functions allow the assessment of mobility, ADLs, and vital signs and can be implemented in a smart home. These functions can also be associated with robots. These robots can provide services and/or act as companions to ease the weight of social isolation [88]. The principal directions in robotics research are task-oriented robots that can assist humans by doing work in a particular environment and interaction-oriented robots that participate in human society. The most highly developed robots in human society today in smart homes are those able to perform tasks such as cutting grass, cleaning rooms, etc. These machines contribute to improving the comfort of human living conditions by performing the task in the place of humans automatically and without constraint. According to a paper focusing on Robot Companions (RC) [89], they can act as:
- Strong machines able to lift objects, assemble artifacts, and perform house work (cleaning, cooking, retrieve and transport objects, etc.);

- Graceful and soft machines (RCs motion and behavior will be graceful, smooth and quiet); and

- Sentient machines with integrated perception, cognition, communication, feeling, action, awareness of self, others and the environment. These machines will execute their tasks in a stereotyped and predefined way; they will be cognizant of the scenario in which they operate and of their human elements. They will be built to understand humans, other animals, physical systems and each other and act accordingly.

RCs are built to target emerging societal challenges, such as the sustainability of urban services, environmental care and monitoring, natural disasters and the general safety of the population.

Home RCs have been developed for elderly people suffering from mild cognitive impairment and living alone at home [90]. The first objective of this project is to develop an RC that is able to provide accompanying services and could truly become the right hand of the person or social caregiver. The social caregiver would become a primary user of the robot as well as the actual care recipient. In their future work, particular attention should be paid to quantifying the long-term effectiveness of socially assistive RCs on the health and well-being of the care recipients.

Globally speaking, robotic aids were first developed for use in industrial production lines and then for domestic tasks, such as cleaning, washing, and transporting objects. Helping citizens and elderly people means developing robots able to, for example, assist handicapped people to grasp objects in their handicapped hand or help lift disabled patients from their beds. It is expected that there will also be RCs that are able to take care of patients well-being (social robots) and take the place of absent parents in conversing with or warning family or formal caregivers that something bad has happened. The future is even expected to bring RCs that will take care of patients health by replacing nurses in taking body temperature, reminding elderly patients to take medicine, and delivering healthcare services (delivering medicine injection or pills on time, performing other nursing tasks, etc.) and well-being services (helping people in their ADLs - eating, dressing, social interactions, etc.).

\section{Hospital versus home healthcare delivery sys- tems: challenges and opportunities}

Society will face big technical challenges and opportunities to make healthcare delivery conform to the new digital era in which people are living. After having examined the convergence of trends that are responsible for most of these challenges, we can observe through the discussion above that the first trend is the computerization and interconnection of medical devices and systems. Computerization and interconnection of PRs and 
medical devices allow for the acquisition, processing, and presentation of an ever-increasing quantity and variety of healthcare data. Interconnected medical devices can bring a more direct, more accurate and rapid information exchange between medical professionals. These combined trends will increasingly transform traditional hospitals and physicians offices into their new digital successors. That means that diagnosis, prevention, and treatment will take place at an earlier stage, with less impact on the patients lifestyle and with more effect as healthcare delivery services occur in the home, office, school, or other non-intrusive community settings with general supervision from hospitals. A major challenge in realizing this goal is the diversity of current healthcare technologies for interchanging data between different medical devices. Until now, the lack of standards between the disparate medical devices has led to a sort of technological tour of Babel. In the absence of effective device-to-device communication interoperability, human operators must read data from one device and transmit it to another, a highly inefficient, time consuming, and error-prone procedure.

The healthcare budget is becoming enormous. For instance, in France, the healthcare budget funded by the national economy is higher than the state budget; its economic weight is broader than human and social weights. Good management (having high quality, efficiency, etc.) of HCSs is essential: with consistent performances, a financial benefit is the possibility of direct investments in the economy. The first possible benefit relates to administrative management that is the initial driving force for change.

\section{Computerized HCSs:}

- Provide each patients EHR so as to accelerate administrative formalities for each medical event (if there is interoperability between the different services);

- Control registered events using smart software (nature, frequency, diagnosis, spending, etc.) and monitor normal behaviors (means and changes);

- Detect irregularities in medical professionals practices, such as multiplication of medical visits, excessive prescribing, etc.

- Perform statistical analysis of human, sociologic and medical quality if the EHRs are well documented and regularly updated;

- Create a patient EHR managed by the patient and comprising measurements gathered at home (ambulatory, programmed measures, etc). Patient EHRs can be easily set up using mean results, and physician access can be allowed during follow-up visits;

- Create a patient EHR managed by the physician that contains information about medical events, visits, diagnosis, and prescriptions;

- Create a hospital EHR that includes results from analyses, recommendations, and specialist prescriptions that can be consulted.

There are also benefits for the patients:
- Reduction of diagnosis errors,

- Better quality of healthcare thanks to computerization,

- Better understanding of behaviors,

- Better analysis of disease evolution,

- Richer exchange between patient and physician,

- Reduction of waiting time, and

- Optimization of hospital stays.

Aside from the advantages of administrative effectiveness, the positive effects on the quality of healthcare delivery and of patients information are real. The availability of a medical record is a necessary passage in the evolution of HCSs. We are interested in this evolution. As medical efficacy is constant or improved, the driving forces of this evolution control the spending and availability of ITs. Reducing the duration of hospital stays and at the same time developing less invasive treatments and surgical procedures are linked to decreases in healthcare expenses mediated by ITs.

Our point of view is that this evolution will operate towards a new equilibrium in the hospital and in the home. This evolution would support controlled access to the patients data for all the concerned actors and reinforce the technology supporting the care of the elderly at home, which we have named MT. The introduction of these new monitoring and home care technologies supposes changes in the practices of all actors and supposes technological innovations that are being established for improved personalized medicine [91]. The evolution scheme that we see for HCSs is shown in Fig. 3.

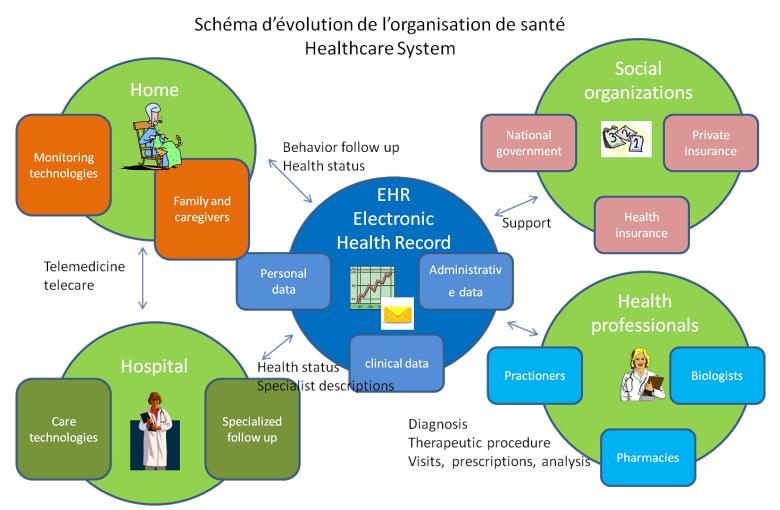

Fig. 3: Possible scheme for a new healthcare organization

One of the essential issues concerning HS using these technologies is the economic issue. The first idea may be solidarity mechanisms: either state mechanisms or private insurances. The solution will likely involve contributions from the patient or his or her family during the transition phase during which the initialization and investment efforts in the changes are particularly high. The scenario that will likely happen is an evolution towards the RM. This solution will first involve prototypes, and then elderly people and their families will be keen on using RM systems to remain independent at home. The key development is on the side of medical establishment, which has to evaluate 
the first procedures to validate the relevance and give prescriptions. Taking into account that these evaluations will take time, we know that all new medicines have to be validated and have to be subject to comparative trials within large groups.

Beneficial effects from the family environment are expected to contribute to these changes. The pressure of demands will surely play an essential role. We are convinced that MTs are the main changing focus of healthcare. In the next decade, baby boomers will begin to reach the age of retirement, and the percentage of Europeans and Americans aged 65 or older will increase from $15 \%$ to $20 \%$. In 2011,40 million people in the United States were aged 65 or over. This number is projected to increase to 89 million by 2050 [92]. In the European Community (EU-28 countries), on January 1, 2013, the population was 505.7 million; this population is projected to be 525.5 million in 2050 . Those aged 65 or over were $18.2 \%$ of the population in 2013; it is projected to be $28.7 \%$ in 2080 [93]. Because of this aging population, healthcare services will increasingly change their focus from acute, episodic care to treatment of long-term chronic diseases. This aging population with chronic illnesses will have high expectations of their HCDSs; such expectations may be made possible by the age of computerization. In this evolution, we have emphasized the prominent role that TLM has to play and the new technical relationship that has to be established between the hospital and the home. The evolution concerns a major re-organization that is being undergone and that involves coordination between numerous actors. Two difficulties have served to slow down this evolution. Healthcare providers have deplored that their field is changing and that financial motivations are important in driving these changes. On the other hand, the driving forces are the patients themselves, who are naturally interested in increasing their health; the insurance companies that have seen benefits of improving HS management; and, of course, industrial enterprises that will have to conceive and manufacture the technical devices.

Concerning MTs, we have identified two axes of interest:

- Early detection of frail people. The stakes are important because preventive actions allow people to live longer in good health. They can benefit from TLM installed in the home. An example of this system is proposed by the project RESPECT [94].

- Monitoring of elderly people. The aim is to have people safe in their homes. Important technological developments have allowed these changes. People can benefit from 24 hours a day TM, remote HS, and remote vital signs measurements.

These changes will become very important in medical practice, but, in a certain aspect, the medical world is the key operator of this evolution, in which the physicians decide whether to prescribe these new technologies.

\section{Conclusion}

Healthcare improvements and cost reductions are made possible by optimizing HCS management of examinations, prescriptions, and monitoring using TM. Essential parts of e-health technologies are now available that allow patients to stay at home in familiar surroundings supported by multiple instruments to monitor, detect, and alarm. Many industries are showing interest for this new business. Investments in the following items have been predicted as being important:

- Materials and software to cover all infrastructure needs,

- Professionals and other people to educate medical teams and give patients confidence.

The business model problem has to be tackled. New materials have to be used; actors and patients have to be educated in this topic. What are the actors in HCSs and what are the ways of progress? We have attempted to analyze how healthcare organizations can evolve by taking advantage of technological progress.

ICTs are being set up. They are aimed at optimizing the hospitals organization of entry data, patient management, EHRs, links between patients and physicians, insured medical fees, and reimbursements. The patient is better taken care by new IT-based HCOs that bring him or her interesting benefits and he can more easily access his/her PRD and discuss issues with his/her physician and specialist.

Introducing MTs is a way of implementing new technologies that are integrated at home or simply worn by the patient into a general HCS. Measuring or monitoring technologies are often embedded into patients suffering from chronic diseases so that patients do not need to stay in the hospital for a long period and may even remain at home living autonomously in normal conditions. We have shown in this paper that IT and wearable solutions are now mature. Prototypes exist throughout the world and it is time to experiment with larger groups of patients.

In this paper, we suggest giving priority to two groups of patients:

- Frail patients who can be active in following up from home. The objective of MT for these patients is to detect health changes early so that these patients can be cured and enjoy a lengthened period of good health.

- People suffering from age-related illnesses who could take advantage of monitoring systems to remain at home safely. Important technological changes will come with the introduction of assistance and companion robots.

We can imagine that monitoring techniques are being applied and developed to meet a natural need of monitoring the robust or frail people who will be equipped with wearable sensors or devices for measuring actimetric and physiological parameters.

The introduction of these ITs and MTs will modify HCDSs at a deep level:

- Hospital platforms will continue to gather the 
most advanced competencies and materials for diagnosis and optimizing internal management, including optimization of specialized services, interface between services, and economic management of hospital stays. The general practitioners will consequently have to organize themselves. They are the undisputed partners that regulate the demands of healthcare services and intervene at home.

- In rural areas, clinics with light medical service could probably use TM to deliver current healthcare services.

Several administrative, social, medical and economic organizations will take charge of the management of these complex HCDSs. Our suggestion is to apply a systems approach of decomposing HCDSs into organizations that are largely autonomous and coordinated by reinforced technological supports.

Of course, it is then necessary to achieve a complete interoperability between all the stakeholders and increased reactivity of HCSs in managing urgent situations, early detection of risk, transportation, and hospital admission.

\section{References}

[1] R. Lenz and M. Reichert, "It support for healthcare processes? premises, challenges, perspectives," Data \& Knowledge Engineering, vol. 61, no. 1, pp. 39-58, 2007.

[2] A. Rosenthal, P. Mork, M. H. Li, J. Stanford, D. Koester, and P. Reynolds, "Cloud computing: a new business paradigm for biomedical information sharing," J. of Biomedical Informatics, vol. 43, no. 2, pp. 342-352, 2010.

[3] P. Simon and D. Acker, "La place de la télémédecine dans l'organisation des soins." Available at: www.sante.gouv.fr/IMG/pdf/Rapport_final_Telemedecine.pdf. Accessed 12 Dec. 2016.

[4] N. van den Berg, M. Schumann, K. Kraft, and W. Hoffmann, "Telemedicine and telecare for older patients? a systematic review," Maturitas, vol. 73, no. 2, pp. 94-114, 2012.

[5] C. Milligan, C. Roberts, and M. Mort, "Telecare and older people: Who cares where?," Social Science $\mathcal{E}$ Med., vol. 72, no. 3, pp. 347-354, 2011.

[6] L. M. Kern, Y. Barrón, R. V. Dhopeshwarkar, A. Edwards, R. Kaushal, and H. Investigators, "Electronic health records and ambulatory quality care," J. of General Internal Med., vol. 28, no. 4, pp. 496-503, 2013.

[7] R. E. Scott, "e-records in health-preserving our future," Int. J. of Medical Informatics, vol. 76, no. 5, pp. 427-431, 2007.

[8] D. Salvi, J. Gorman, M. T. Arredondo, C. Vera-Munoz, M. Ottaviano, and S. Salvi, "A platform for the development of patient applications in the domain of personalized health," Computer Methods and Programs in Biomed., vol. 107, no. 1, pp. 45-52, 2012.

[9] S. Rao, C. Brammer, A. McKethan, and M. B. Buntin, "Health information technology: transforming chronic disease management and care transitions," Primary Care: Clinics in Office Practice, vol. 39, no. 2, pp. 327-344, 2012.

[10] J. R. Shah, M. B. Murtaza, and E. Opara, "Electronic health records: challenges and opportunities," J. of Int. Technology and Inf. Management, vol. 23, no. 3, pp. 189-204, 2014.

[11] I. R. Bardhan and M. F. Thouin, "Health information technology and its impact on the quality and cost of healthcare delivery," Decision Support Systems, vol. 55, no. 2, pp. 438-449, 2013.

[12] A. T. Association, "Arizona and montana governors sign telemedicine bills into law." Available at: http://dev.americantelemed.org/newslanding/2013/04/10/arizona-and-montana-governorssign-telemedicine-bills-into-law. Accessed 12 Dec. 2016.
[13] A. L. Neves, "French boost european telemedicine," Canadian Medical Assoc. J., vol. 183, no. 7, pp. 387-388, 2011.

[14] P. Suter, W. N. Suter, and D. Johnston, "Theory-based telehealth and patient empowerment," Population Health Management, vol. 14, no. 2, pp. 87-92, 2011.

[15] C. Juhne and A. C. Mühlbacher, "Patient-centeredness in integrated healthcare delivery systems - needs, expectations and priorities for organized healthcare systems," Int. J. of Integrated Care, vol. 13, p. e051, 2013.

[16] L. R. Martin, S. M. Williams, K. B. Haskard, and M. R. DiMatteo, "The challenge of patient adherence," Therapeutics and Clin. Risk Management, vol. 1, no. 3, pp. 189-199, 2005.

[17] P. A. Clark, K. Capuzzi, and J. Harrison, "Telemedicine: Medical, legal and ethical perspectives," Medical Science Monitor: Int. J. of experimental and Clin. Research, vol. 16, no. 12, pp. 261272, 2010.

[18] G. Siegal, "Telemedicine: licensing and other legal issues," Otolaryngologic Clinics of North America, vol. 44, no. 6, pp. 1375-1384, 2011.

[19] "Sécurité sociale." Available at: http://www.securitesociale.fr. Accessed 12 Dec. 2016.

[20] "Health at a glance in europe 2014." Available at: https: / / ec.europa.eu/health/home_en.pdf. Accessed 12 Dec. 2016.

[21] "Oecd reviews of health care quality: Denmark raising standards, oecd publishing." Available at: http:/ / dx.doi.org/10.1787/9789264191136-en.

[22] C. Georges, D. Whitehouse, and P. Duquenoy, eHealth: Legal, Ethical and Governance Challenges. Springer-Verlag Berlin Heidelberg, 2013.

[23] T. Marmor and C. Wendt, "Conceptual frameworks for comparing healthcare politics and policy," Health Policy, vol. 107, no. 1, pp. 11-20, 2012.

[24] R. Thakur, S. H. Y. Hsu, and G. Fontenot, "Innovation in healthcare: Issues and future trends," J. of Business research, vol. 65, no. 4, pp. 562-569, 2012.

[25] R. A. Rosenblatt and L. G. Hart, "Physicians and rural america," Western J. of Med., vol. 173, no. 5, pp. 348-351, 2000.

[26] R. Amarasingham, L. Plantinga, M. Diener-West, D. J. Gaskin, and N. R. Powe, "Clinical information technologies and inpatient outcomes, a multiple hospital study," Archives of Internal Med., vol. 169, no. 2, pp. 108-114, 2009.

[27] P. Vegoda, "Introducing the ihe (integrating the healthcare enterprise) concept," J. of Healthcare Inf. Management, vol. 16, no. 1, pp. 22-24, 2002.

[28] C. M. Desroches, R. G. Campbell, S. R. Rao, K. Donelan, T. G. Ferris, A. Jha, and al, "Electronic health records in ambulatory care? a national survey of physicians," New England J. of Med., vol. 359, no. 1, pp. 965-970, 2008.

[29] J. Adler-Milstein and D. W. Bates, "Paperless healthcare: progress and challenges of an it-enabled healthcare system," Business Horizons, vol. 53, no. 2, pp. 119-130, 2010.

[30] R. G. Fichman, R. Kohli, and R. Krishnan, "The role of information systems in healthcare: current research and future trends," Inf. Systems Research, vol. 22, no. 3, pp. 419-428, 2011.

[31] C. Wendt, "Mapping european healthcare systems: A comparative analysis of financing, service provision and access to healthcare," J. of Eur. Soc. Pol., vol. 19, no. 5, pp. 432-445, 2009.

[32] J. E. Bardam, "Pervasive healthcare as a scientific discipline," Methods of Inf. in Med., vol. 47, no. 3, pp. 178-185, 2008.

[33] K. Hobson, "Critics take aim at high-tech care," U.S News $\mathcal{E}$ World Report, vol. 146, no. 7, pp. 76-78, 2009.

[34] H. Lester and F. D. R. Hobbs, "Major policy changes for primary care : potential lessons for the us new model of family medicine from the quality and outcomes framework in the united kingdom," Family Med., vol. 39, no. 2, pp. 96$102,2007$.

[35] J. M. Renard, R. Beuscart, D. Delerue, and J. M. Geib, “The inter-regional medical information system: a new form of communication between healthcare providers," ITBM-RBM, vol. 21, no. 5, pp. 275-280, 2000.

[36] J. M. Renard, J. F. Kulik, R. Beuscart, and J. M. Geib, "Intermediation: a new concept for medical data exchanges," in First Joint BMES/EMBS Conference, vol. 2, (USA (Atlanta, GA)), October 1999. 
[37] C. Abraham, E. Nishihara, and M. Akiyama, "Transforming healthcare with information technology in japan: a review of policy, people, and progress," Int. J. of Medical Informatics, vol. 80, no. 3, pp. 157-170, 2011

[38] F. Barbarito, F. Pinciroli, J. Mason, S. Marceglia, and L. Mazzola, "Implementing standards for the interoperability among healthcare providers in the public regionalized healthcare information system of the lombardy region," J. of Biomedical Informatics, vol. 45, no. 4, pp. 736-745, 2012.

[39] N. Al-Qirim, "Championing telemedicine adoption and utilization in healthcare organizations in new zealand," Int. J. of Medical Informatics, vol. 76, no. 1, pp. 42-54, 2007.

[40] A. Lymberis and S. Olsson, "Intelligent biomedical clothing for personal health and disease management: State of the art and future vision," Telemed. J. and e-Health, vol. 9, no. 4, pp. 379-386, 2003.

[41] B. Charles, "Telemedicine can lower costs and improve access," Healthcare Financial Management Assoc., vol. 54, no. 4, pp. 66-69, 2000

[42] S. Edelstein, "Careful telemedicine planning limits costly liability exposure," Healthcare Financial Management Assoc., vol. 53, no. 2, pp. 63-69, 1999.

[43] M. Chan, D. Estève, C. Escriba, and E. Campo, "A review of smart homes-present state and future challenges," Computer Methods and Programs in Biomed., vol. 91, no. 1, pp. 55-81, 2008.

[44] J. Flower, The future of healthcare. Encyclopedia of the Future, Macmillan and Company, 1996.

[45] N. Genet, W. G. W. Boerma, D. S. Kringos, A. Bouman, A. L. Francke, C. Fagerström, M. G. Melchiorre, C. Greco, and W. Devill, "Home care in europe: a systematic literature review," BMC Health Services Research, vol. 11, pp. 16-18, 2011.

[46] N. M. Hjelm, "Benefits and drawbacks of telemedicine," J. of Telemed. and Telecare, vol. 11, no. 2, pp. 60-70, 2005.

[47] A. G. Ekeland, A. Bowes, and S. Flottor, "Effectiveness of telemedicine: A systematic review of reviews," Int. J. of Medical Informatics, vol. 79, no. 11, pp. 736-771, 2010.

[48] A. K. Parekh, R. A. Goodman, C. Gordon, and H. K. Koh, "Managing multiple chronic conditions: A strategic framework for improving health outcomes and quality of life," Public Health Reports, vol. 126, no. 4, pp. 460-471, 2011.

[49] S. C. Inglis, R. A. Clark, F. A. McAlister, S. Stewart, and J. G. Cleland, "Which components of heart failure programmes are effective? a systematic review and meta-analysis of the outcomes of structured telephone support or telemonitoring as the primary component of chronic heart failure management in 8323 patients: Abridged cochrane review," European J. of Heart Failure, vol. 13, no. 9, pp. 1028-1040, 2011.

[50] G. Gibelli, B. Gibelli, and F. Nani, "Thyroid cancer: possible role of telemedicine," Acta Otorhinolaryngol Italica, vol. 28, no. 6, pp. 281-286, 2008

[51] H. Hoenig, J. A. Sanford, T. Butterfield, P. C. Griffiths, P. Richardson, and K. Hargraves, "Development of a teletechnology protocol for in-home rehabilitation," J. of Rehabilitation Research and Development, vol. 43, no. 2, pp. 287-298, 2006.

[52] N. V. Halifax, J. A. Cafazzo, M. J. Irvine, and al, "Telemanagement of hypertension: A qualitative assessment of patient and physician preferences," Canadian J. of Cardiology, vol. 23, no. 7, pp. 591-594, 2007

[53] S. McLean, D. Chandler, U. Nurmatov, J. Liu, C. Pagliari, J. Car, and A. Sheikh, "Telehealthcare for asthma: a cochrane review," Canadian Medical Assoc. J., vol. 183, no. 11, pp. 733742, 2011.

[54] J. Franek, "Home telehealth for patients with chronic obstructive pulmonary disease (copd)," Ontario Health Technology Assessment Series, vol. 12, no. 11, pp. 1-58, 2012.

[55] "World population ageing 2013." Available at: http://www.un.org/esa/population. Accessed 12 Dec. 2016.

[56] M. C. McDermid, H. T. Stelfox, and S. M. Bagshau, "Frailty in the critically ill: a novel concept," Critical Care, vol. 15, no. 1, p. 301, 2011.

[57] Q. L. Xue, "The frailty syndrome: definition and natural history," Clinics in Geriatric Med., vol. 27, no. 1, pp. 1-15, 2011.

[58] S. Hagler, D. Austin, T. L. Hayes, T. Kaye, and M. Pavel, "Unobtrusive and ubiquitous in-home monitoring: a method- ology for continuous assessment of gait velocity in elders," IEEE Trans. on Biomed. Eng., vol. 57, no. 4, pp. 813-820, 2010.

[59] J. Vermeulen, J. C. L. Neyens, E. van Rossum, M. D Spreeuwenberg, and L. P. de Witte, "Predicting adl disability in community-dwelling elderly people using physical frailty indicators: a systematic review," BMC Geriatrics, vol. 11, no. 1, p. 33, 2011.

[60] Z. Bien and S. W. Lee, "Learning structure of human behavior patterns in a smart home system," Quantitative Logic and Soft Computing (Advances in intelligent and Soft Computing), vol. 82, pp. 1-15, 2010.

[61] W. Bourennane, Y. Charlon, F. Bettahar, M. Chan, D. Estève, and E. Campo, "Ambient intelligence for monitoring alzheimer patients," Int. J. of E-Health and Medical Communications, vol. 4, no. 1, pp. 23-35, 2013.

[62] W. Bourennane, F. Bettahar, and E. Campo, "Self adaptive trajectory learning for monitoring the elderly wandering," in Int. Conference on Biomedical Engineering (BIOMED), (Austria (Innsbruck)), p. 6p, February 2013.

[63] S. C. Peirce, A. R. Hardisty, A. D. Preece, and G. Elwyn, "Designing and implementing telemonitoring for early detection of deterioration in chronic disease: defining the requirements," Health Informatics J., vol. 17, no. 3, pp. 173-190, 2011.

[64] J. C. van Haastreqt, E. van Rossum, J. P. Diederiks, L. P. de Witte, P. M. Voorhoeve, and H. F. Crebolder, "Processevaluation of a home visit programme to prevent falls and mobility impairments among elderly people at risk," Patient Education and Counceling, vol. 47, no. 4, pp. 301-309, 2002.

[65] E. R. Larsen, L. Mosekilde, and A. Foldspang, "Determinants of acceptance of a community based program for the prevention of falls and fractures among the elderly," Preventive Med., vol. 33, no. 2, pp. 115-119, 2001.

[66] E. Dishman, "Inventing wellness systems for aging in place," Computer, vol. 37, no. 5, pp. 34-41, 2004.

[67] D. Hoch and T. Ferguson, "What i've learned from e-patient," PloS Med., vol. 2, no. 8, p. e206, 2005.

[68] M. M. Funnell, "Helping patients take charge of their chronic illnesses," Family Practice Management, vol. 7, no. 3, pp. 47-51, 2000.

[69] "Insee." Available at: http://www.insee.fr/fr/themes/ document.asp?ref_id=ip1340. Accessed 12 Dec. 2016.

[70] S. Koch, M. Marschollek, K. H. Wolf, M. Plischke, and R. Haux, "On health-enabling and ambient-assistive technologies - what has been achieved and where do we have to go?," Methods of Inf. in Med., vol. 48, no. 1, pp. 29-37, 2009.

[71] L. P. Kaelbing, M. L. Littman, and A. W. Moore, "Reinforcement learning: A survey," J. of Artificial Intelligence Research, vol. 4, pp. 237-285, 1996

[72] M. Chan, E. Campo, and D. Estève, "Prosafe, a multisensory remote monitoring system for the elderly or the handicapped," in Int. Conference On Smart homes $\mathcal{E}$ health Telematics, (Canada (Montreal, PQ)), p. 7p, June 2011.

[73] T. S. Barger, D. E. Brown, and M. Alwan, "Health-status monitoring through analysis of behavioral patterns," IEEE Trans. on Systems, Man and Cybernetics, part A: Systems and humans, vol. 35 , no. 1, pp. 22-27, 2005.

[74] R. Hamid, S. Maddi, A. Johnson, A. Bobick, I. Essa, and C. Isbell, "A novel sequence representation for unsupervised analysis of human activities," Artificial Intelligence, vol. 173, no. 14, pp. 1221-1244, 2009.

[75] P. Rashidi, D. J. Cook, L. B. Holder, and M. SchmitterEdgecombe, "Discovering activities to recognize and track in a smart environment," IEEE Trans. on Knowledge and Data Engineering, vol. 23, no. 4, pp. 527-539, 2011.

[76] J. Boger, J. Hoey, P. Poupartg, C. Boutilier, G. Fernie, and A. Mihailidis, "A planning system based on markov decision processes to guide people with dementia through activities of daily living," IEEE Trans. on Inf. Technology in Biomed., vol. 10, no. 2, pp. 323-333, 2006.

[77] T. Tamura, J. Zhou, H. Mizukami, and T. Togawa, "A system for monitoring temperature distribution in bed and its application to the assessment of body movement," Physiological Measurement, vol. 14, no. 1, pp. 33-43, 1993.

[78] M. Chan, D. Estève, J. Fourniols, C. Escriba, and E. Campo, "Smart wearable systems: Current status and future chal- 
lenges," Artificial Intelligence in Med., vol. 56, pp. 137-156, 2012.

[79] R. E. Herzlinger, "Healthcare reform and its implications for the u.s. economy," Business Horizons, vol. 53, no. 2, pp. 105$117,2010$.

[80] Z. Ma, "An electronic second skin," Science, vol. 333, no. 6044, pp. 830-831, 2011.

[81] A. J. Chung, D. Kim, and D. Erickson, "Electrokinetic microfluidic devices for rigid, low power drug delivery in autonomous microsystems," Lab on Chip, vol. 8, no. 2, pp. 330$338,2008$.

[82] J. Lueke and W. A. Moussa, "Mems-based power generation techniques for implantable biosensing applications," Sensors, vol. 11, no. 2, pp. 1433-1460, 2011.

[83] A. R. Eliakim, "Video capsule endoscopy of the small bowel (pillcam sb)," Current opinion in gastroenterology, vol. 29, no. 3, pp. 133-139, 2013.

[84] Carmat. Available at: http://www.carmatsa.com. Accessed 12 Dec. 2016.

[85] AWAK, "Automated wearable artificial kidney." Available at: http:/ /www.awak.com. Accessed 12 Dec. 2016.

[86] A. Davenport, "Portable or wearable peritoneal devices the next stop forward for peritoneal dialysis?," Advances in Peritoneal Dialysis, vol. 28, pp. 97-101, 2012.

[87] H. D. Humes, D. Buffington, A. J. Westover, S. Roy, and W. H. Fissel, "The bioartificial kidney: current status and future promise," Pediatric Nephrology, vol. 29, no. 3, pp. 343-351, 2014.

[88] T. S. Dahl and M. N. K. Boulos, "Robots in health and social care: A complementary technology to home care and telehealthcare?," Robotics, vol. 3, no. 1, pp. 1-21, 2013.

[89] P. Dario, P. F. M. J. Verschure, T. Prescott, G. Cheng, G. Sandini, R. Cingolani, and al, "Robot companions for citizens," Procedia Computer Science, vol. 7, pp. 47-51, 2011.

[90] H. M. Gross, C. Schroeter, S. Mueller, M. Volkhardt, E. Einhorn, A. Bley, C. Martin, T. Langner, and M. Merten, "Progress in developing a socially assistive mobile home robot companion for the elderly with mild cognitive impairment," in IEEE/RJS, Int. Conference on Intelligent Robots and Systems, (USA (San Francisco, CA)), pp. 2430-2437, September 2011.

[91] M. G. Aspinall and R. G. Hamermesh, "Realizing the promise of personalized medicine," Harvard Business Review, vol. 85, no. 10 , pp. 108-117, 2007.

[92] "Population reference bureau." Available at: http:/ / www.prb.org/pdf11/aging-in-america.pdf. Accessed 12 Dec. 2016.

[93] “Eurostat." Available at: http:/ /ec.europa.eu/info/publications / strategic-plan-2016-2020-eurostat_en. Accessed 12 Dec. 2016.

[94] A. Piau, Y. Charlon, E. Campo, B. Vellas, and F. Nourhashemi, "A smart insole to promote healthy aging for frail elderly individuals: Specifications, design, and preliminary results protocol," JMIR Rehab. and Assist. Technol., vol. 2, no. 1, p. e5, 2015.

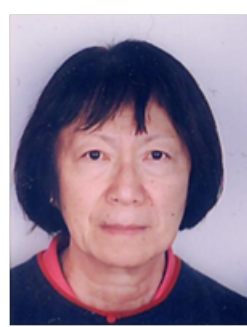

Marie Chan has received the $\mathrm{PhD}$ in $\mathrm{Ap}$ plied Mathematics from the University of Toulouse, France. In charge of research at INSERM, she was first involved in data analysis, pattern recognition, diagnosis and decision support. She has been working in LAAS-CNRS since 1992. She has developed intelligent multisensor monitoring systems to help elderly and disabled living autonomously in secure home environment.

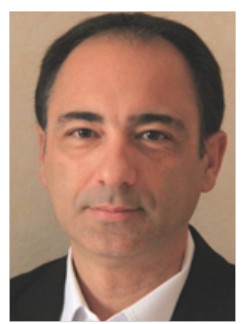

Eric Campo is a Professor at the University of Toulouse. He conducts research in LAAS-CNRS Laboratory on the design and development of communicating multisensor systems, embedded in human or in his environment, in the context of distributed instrumentation. He is responsible for the Smart Sensing and Systems Monitoring research team at LAAS and responsible for the Living Lab at the technology institute of Blagnac.

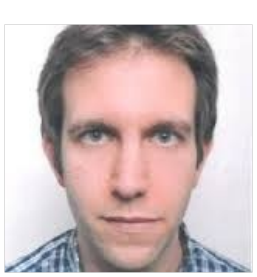

Damien Brulin is an Associate Professor at LAAS-CNRS and technology institute of Blagnac. He obtained his PhD degree in 2010 in automatic and data treatment and he is currently working on smart integrated system for people monitoring and data analysis based on expert systems.

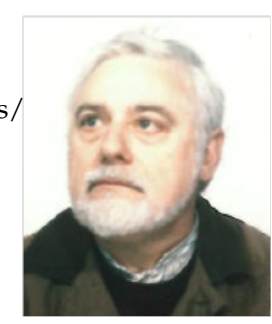

Daniel Estève is Emeritus research Director at LAAS-CNRS. He has historically contributed to the technological development of microelectronics devices and circuits as a specialist in surface effects in semiconductors and has participated in the emergence of nanotechnologies and micronanosystem integrations over the last twenty years. He is currently working on systems engineering in the field of supervision systems in different types of applications: energy systems, elderly monitoring and others. 